\title{
Identification of Thai students' level of phonetic sensitivity in the imitation of Russian syllables
}

\author{
Mekratankulpat Natcheewan $^{1, *}$, Nina Fedotova ${ }^{1}$, and Tatiana Lypkan ${ }^{1}$ \\ ${ }^{1}$ St. Petersburg State University, 199034, 13B Universitetskaya Emb., St. Petersburg, Russia
}

\begin{abstract}
The article deals with the role of phonological sensitivity in the development of skills in a foreign language. In psycholinguistic terms, verbal communication in non-native language is a language contact. It is important that, in learning environments, the interaction of contacting languages should not be spontaneous, it should be taken into account in the modeling of verbal communication. Since the formation of mechanisms that ensure the speech activity of an individual in the language under study occurs under the influence of interference, it is necessary to study the manifestation of the specifics contacting linguistic systems in the perception of speech in a non-native language. To make the right decision - whether or not an incorrect perception of the phonemic composition of words occurs in the natural conditions of communication in a foreign language - is not possible. This requires a special phonetic experiment. The authors describe the results of an experiment aimed at revealing the phonetic sensitivity of native speakers of Thai. The material of the experiment was 260 syllables having the structure CV (consonant + vowel). Subjects who had not previously studied the Russian language had to listen to audio recordings of syllables pronunciation and reproduce them. Thus, the implementation of Russian vowels and consonants in the composition of syllables was analyzed. The authors succeeded in revealing the similarity and difference in the articulatory characteristics of the interacting languages' sounds. It was found that when imitating Russian syllables the Thais are not aware of the opposition of consonants on the grounds of "hardness-softness" and "voiceless-voiced". In this connection special work is required to produce soft sounds and to develop skills for distinguishing sounds from voicelessvoiced. During the study, it was confirmed that the influence of the native language is clearly manifested if it is functionally prevalent.
\end{abstract}

\section{Introduction}

In the 1990's an active study of the role of phonological sensitivity in the development of reading and spelling skills began, which led to a wide application of this term by many researchers in various fields: education, speech therapy and psychological clinical practice [9].

* Corresponding author: natcheewan@gmail.com 
During the study of the academic sources it was proved that there are almost no works in which the term 'phonetic sensitivity' is defined. Moreover, the terms 'language sensitivity' and 'auditory differential sensitivity' were mainly used as synonyms.

A. V. Shchepilova believes that "the most independent of other ability elements to foreign languages is phonetic sensitivity. It is the ability to analyze incoming sounds, identify them, encode and reproduce the sounds of foreign speech. Phonetic sensitivity does not depend on either grammatical abilities or the degree of development of the student's memory type, although it is directly related to the ability to establish associations between a letter and a sound. A student who does not speak well will not read well, and vice versa. Phonetic sensitivity is most dependent on genetic factors" [22].

Concerning the term "auditory differential sensitivity," Frolov writes that this is "the ability of a person (with sufficient memory) to linguistic coding at the intonationphonological level. This is a person's ability to establish the difference in the differentiating characteristics of phonemes and their variants, intonem, identify them in the flow of speech and adequately imitate" [8].

\section{Problem Statement}

As for the definition of the term "language sensitivity," this term is understood differently, depending on the approach to the study of language abilities. In the work of E. Kh. Karpovnikova, it is noted that "the expression "language sensitivity" belongs to L. I. Aidarova and stands in a number of such names manifestation of the language ability phenomenon, as a gift of speech, language flair, linguistic feeling, language information, language conjecture" [11].

There is no unambiguous interpretation of the term "linguistic flair," which is confirmed by the thesis work of T. M. Kolesnikova. Nevertheless, many scientists recognize the existence of this ability. Linguists (V. von Humboldt, F. de Saussure, I. A. Baudouin de Courtenay, F. I. Buslaev, A. A. Potebnya, I. I. Sreznevsky, L. V. Shcherba) wrote about the presence of linguistic instincts, as well as psychologists (L. S. Vygotsky, A. R. Luria, N. I. Zhinkin, S. F. Zhuikov) and methodologists (K. D Ushinsky, L. P. Fedorenko, N. S. Rozhdestvensky) do. However, in different concepts, this phenomenon has received different names: the gift of speech, the language ability, the language flair, the language sense, the language intuition, the language conjecture. These concepts are also interpreted ambiguously" [13].

Coping with the lack of a generally accepted understanding of this term, we should turn to dictionaries. In the encyclopaedic dictionary of psychology and pedagogy, the term "linguistic flair" is interpreted as "a sense of language, style, thanks to which the individual strives to express his thoughts stylistically, competently and irreducibly, unconventional and experiencing a specific awkwardness, noticing the verbal errors of the interlocutor, finely feels the slightest speech, stylistic inaccuracies" [26]. Obviously, the term "linguistic flair" is viewed more like using language as a means of expressing a particular feeling, and not as person's abilities in the process of forming linguistic skills.

\section{Research Questions}

For the purposes of our research, we consider the understanding of "linguistic sensitivity" as an ability to perceive and imitate foreign sounds to be the most acceptable. E. A. Kislitsyna conducted an experiment to identify the ability of Chinese students to perceive and imitate Russian sounds and called this ability a language sensitivity [12]. On the basis of what has been said, it can be concluded that the terms "phonetic sensitivity" and "auditory differential 
sensitivity" are equivalent and denote the individual's ability to distinguish, identify, and encode the heard sounds of a foreign language. In our opinion, these terms are narrower than "linguistic sensitivity," using of which, as applied to the phonetic aspect of communication, is not entirely justified. To clarify the term "phonetic sensitivity" we turned to Englishlanguage sources. It has been found that researchers use two terms: "phonetic / phonological sensitivity" and "phonetic / phonological / phonemic awareness," with preference given to the term "phonological awareness." In the work of G. T. Gillon, it was noted that the term "phonological awareness" appeared in the academic literature in the late 1970's and early 1980 's and was interpreted as the individual's comprehension of the sound system or the phonological structure of the sounding word. This term was used to describe the process of forming reading skills among children. In earlier works it was argued that understanding the sound system of a word enables children to encode (or pronounce) a printed word $[4 ; 6 ; 7$; $15 ; 16$ et al.]. Then in 1980, A. J. Marcel was one of the first to establish a direct link between phonological sensitivity and spelling error, proving that an individual who tolerates such errors has a low level of phonological sensitivity [18].

However, an opinion about the difference between the terms 'phonological awareness' and 'phonological sensitivity' could be found. In the article "A Developmental Continuum of Phonological Sensitivity Skills" Lisa A. Pufpaff notes that the term 'phonological sensitivity' was introduced by K.E. Stanovich (1992) to describe a set of skills related to phonological processing that is used in the reproduction of speech sounds [20, 679]. K. E. Stanovich believes that "phonological sensitivity should be viewed as a continuum from 'deep' sensitivity to 'shallow' sensitivity. Tasks indicating deeper levels of sensitivity require more explicit reports of smaller sized units [23, p.317]. In other words, the author believes that phonetic sensitivity should be viewed as a continuous command from "deep" sensitivity to "superficial". A deeper level of sensitivity means having accurate information about the simplest units. Thus, according to the author, the term 'phonological sensitivity' has a wide meaning, embracing also 'phonological awareness', since 'phonological awareness' most often means only the ability to identify and reproduce the heard sound (allophone), but not to reveal the differential signs of the phoneme. In the following discussion, we will use the term "phonetic sensitivity" to denote the individual's ability to produce phonological processing of the heard sound and implement it in accordance with the results of such processing.

\section{Purpose of the Study}

The purpose of this experimental study in detecting the level of phonetic sensitivity in speakers of Thai language was predominantly exploratory [24]. To determine the level of phonetic sensitivity among the Thais to the perception and imitation of Russian sounds audio recordings of 260 syllables pronunciation having the structure of CV (consonant + vowel) were used. Syllables were recorded by the bearer of the literary norm of the Russian language, a resident of St. Petersburg. The recording was made in a professional recording studio. Consonant sounds in syllables are opposed by hardness - softness (eg, ba-ba), by voiceless voiced (eg, pa-ba), also by consonant - vowel (eg la-l'a). Consonant sounds in syllables are divided into 4 groups:

- Noisy labial consonants /p-p'/, /b-b'/,/f-f'/,/v-v'/;

- Noisy front-line consonants /t-t'/, /d-d'/,/s-s'/,/z-z'/, /š-ž/, /š's/, /c/, /c'/;

- Noisy back-language consonants $/ \mathrm{k}-\mathrm{k} \% /, / \mathrm{g}-\mathrm{g} \% /, \mathrm{x}-\mathrm{x}^{\prime} /$;

- Sonants $/ \mathrm{m}-\mathrm{m} \%$, /n-n'/, / - $1 \% /, / \mathrm{r}-\mathrm{r} \% /, / \mathrm{j} \%$.

All vowel phonemes of the Russian language are presented in the experiment:

- Vowel /e/ - front row, medium lift, unbounded;

- Vowel /i/ - front row, highest lift, unbounded; 
- Vowel /o/ - back row, medium lift, bounded;

- Vowel /u/ - back row, high lift, rounded;

- Vowel /it - heterogeneous in a row, high rise, unbounded;

- Vowel /a/ - back row, lowest lift, unbounded [3, p. 25].

\subsection{Subjects}

To reveal the level of phonetic sensitivity of the Thais, we conducted an experiment in which 10 native speakers of Thai language ( 5 men and 5 women) took part. The age of the participants is from 18 to 28 years.

All subjects are residents of Bangkok. 5 subjects work in areas not related to the usage of foreign language, while others are students of non-linguistic universities.

All participants in the experiment have certain command in English as their first foreign language, which is varied from A2 to $\mathrm{C} 1$ level of English as foreign language. One subject speaks fluently not only English but also Japanese and is currently studying German.

In order to obtain reliable results, the Thais, who had not previously studied the Russian language, were specifically selected for the group of subjects.

\subsection{Experiment Procedure}

The experiment was conducted distantly. All participants in the experiment were sent an electronic audio recording of Russian syllables' pronunciation. The audio was supplied by an instruction in Thai: "Listen to the syllables and repeat them after the announcer in pauses. Record your pronunciation using the voice recorder of your mobile phone. You can listen to each syllable only once". Then the testers had to send their audio recordings to the experimenter by an e-mail.

\section{Research Methods}

During the experiment, the simulation was used with no written support. According to a number of researchers, an imitation, being understood as "the repetition of sounds, words, phrases after a teacher or announcer in sound recording" [1], is an almost ideal way of obtaining a large volume of phonetic information, since under these conditions the speech behavior of an individual is more automated compared with the letter record heard $[5,10]$. An obvious advantage of this method of research is that the recipient is not "imposed" by an artificial phonemic classification [21]. Important is the dependence of the simulation results on the interaction of the sensory and motor levels $[14,19$, etc. $]$.

\section{Findings}

Thai-Russian interference is clearly manifested at all levels of the Russian language's phonological component, i.e. on segmental as well as on suprasegmental. This is due to the typological dissimilarity of Thai and Russian.

An analysis of the results of our experiment shows that Thai subjects had difficulty reproducing Russian sounds. Violations of the differential and integral phonemes' signs were detected.

Let us discuss the results of auditory phonetic analysis of the Russian syllables' imitation by speakers of the Thai language.

\subsection{Vowels}




\section{$6.1 .1 / a /$}

Position /a/ in combinations with prepositional hard consonants does not cause particular

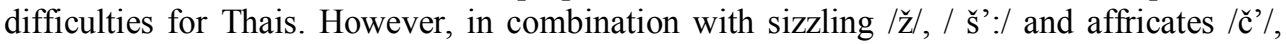
phonetic disturbances (3.6\% of the total number of syllables) are found. In these combinations, the phoneme allophone [a] was recognized as an open vowel in the front row of the middle ascent [æ] (3.2\%) and as a diphthong [ua] (0.4\%).

In the position after soft consonants, systemic violations of the vowel / a / are noted, since in this position it is characterized by diphthongoidity (heterogeneity) - [ia], which is not characteristic of the Thai phonetic system. However, according to the experimental data, there is a possibility that the Thais can normatively realize this sound $(3.3 \%$ of the subjects were reproduced by the diphthongoid vowel). But in most cases allophone [ia] was pronounced as a combination of [ia] $(69.6 \%$ of violations). Other realized variants are monophthongs [a] $(17,3 \%)$, [æ] $(8,6 \%)$ and [e] $(1,2 \%)$.

\subsubsection{The vowel /el}

The Russian allophone of the phoneme /e/ in combination with hard consonants is the vowel of the front row of the middle rise, which coincides with the Thai [æ] both in the series and in the ascent. Accordingly, when simulating this allophone in most cases was implemented correctly. The phonetic deviations in the simulation of this sound were relatively small $(8.4 \%)$ : the Thai closed vowel of the front row of the middle rise $[\varepsilon](4.5 \%)$ and the vowel of the back row of the upper-average rise [u] $(0.4 \%)$ were pronounced. In addition, the pronounced diphthongs [ei] $(2.7 \%)$, [wa] $(0.4 \%)$ and [ia] $(0.4 \%)$ were recorded.

Reproduction of the diphthongoid [i] in a position with soft consonants caused special difficulties for Thais. In most cases, this allophone was pronounced as a combination of vowels [ie] (87.6\%), mostly in combination with soft noisy labial /p'/, /b\%, /f'/ and sonants $/ \mathrm{m} \%, / \mathrm{n} \%, / \mathrm{r} \%$. The variant of diphthong [ei] realization in the place of the Russian allophone (4.4\%) was also noted, mainly in syllables with soft noisy front consonants $/ \mathrm{t}$ '/, /s'/, /šs, /šs':/, $/ \check{c}$ '/. In addition, monophthongs [æ] (6\%), [i] (1\%) and [a] (1\%) were reproduced on the site of the allophone [ie].

\subsubsection{Vowel/t/}

Reproduction of this vowel in combination with hard consonants does not seem problematic for Thais. This is because the articulation of the Russian [i] has a similarity to the articulation of the Thai vowel sound of the back row of the upper rise [u]. Accordingly, during imitation, almost all participants in the experiment pronounced the sound of their native language [u] (92.2\% of the subjects). Nevertheless, other variants of violation of the Russian language's phonetic norms $(7.8 \%)$ were also found in the analysis: the realization of diphthong [iu] (2.8\%), monophthongs [i] $(2.3 \%)$, [æ] $(2.3 \%)$ and [e] $(0.4 \%)$.

It is known that in the absolute end of the Russian syllable / word in the vowel / $\mathbf{i}$ / appears an [i] -shaped sound. It could be assumed that in this position the Thais will pronounce the diphthong [uil], however in our experiment such implementations were not noted.

\subsubsection{The vowel /i/}

The realization of the allophone [i] in the position after soft consonants caused some difficulties for the Thais, despite the fact that in Thai there is a corresponding vowel of the front row of the upper rise [i]. The number of syllables with an erroneous pronunciation was $17.3 \%$ : the realization of monophthongs [6.2], [u] (1.2\%), [æ] (0.6\%) and diphthong [ia] (9, $3 \%)$. Most of the violations are noted in syllables with sonants $/ 1 \% /, / \mathrm{r} /$ and with an affricate $/ \mathrm{c} /$. 


\subsubsection{The vowel /o/}

The implementation of $/ \mathrm{o} /$ in the position after hard consonants in most cases was not difficult for Thai subjects, since in their native language there is an acoustically similar vowel of the back row of medium rise [o]. However, some participants made mistakes in the articulation of the diphthongoid allophone [uo]. The number of erroneous syllables is small $(9.7 \%)$. The variants of the disturbances are the realization of diphthongs [ou] $(1.5 \%)$, [oi] $(0.8 \%)$, [ua] $(0.4 \%)$, and monophthongs [e] $(0.4 \%)$, [u] $(0.4 \%)$, [iu] $(0.4 \%)$, but most often in syllables with a noisy labial $/ \mathrm{b} /$ and an affricate / $\breve{c} /$ on the place [uo] was realized [io] $(5.8 \%)$.

Since in the Russian language in the post-soft consonant position there is a combinatorial variation of the vowels associated with the palatalization of the prepositional consonant, an allophone [yo] is formed in the syllable syllables. Thais, when listening to syllables, apparently caught this feature and pronounced the Thai not unbounded vowel of the back row of the average rise $[\gamma](17,6 \%)$. But at the same time, despite the absence of diphthongoid in this Thai vowel, $22.9 \%$ of Thai subjects managed to reproduce it correctly. Most of the participants in the experiment were able to realize the sound [yo] at the position after noisy front-consonants $/ \mathrm{t} /, / \mathrm{d}$ '/ and sonants $/ \mathrm{m} \%, / \mathrm{n} \%$. Nevertheless, various variants of erroneous implementation were recorded. In some cases, the vowel [yo] was reproduced as a Thai vowel of full time vowel [o] (44.5\%). Other variants of realization: monophthongs [u] $(2.6 \%)$, diphthongs [ia] (5.9\%), [i] (3.3\%), [ua] (1.3\%), [ou] (0.65\%) and a combination of sounds [ir] (1.3\%). The largest number of violations was recorded in syllables with sonants $/ \mathrm{r} /, / 1 \%$, $/ \mathrm{m} \%$, with lip stop and gap consonants $/ \mathrm{p} \%, / \mathrm{b} \%, / \mathrm{f} /, / \mathrm{v} \%$ and voiceless whistling $/ \mathrm{s} \%$

\subsubsection{The vowel /u/}

The Russian vowel $[\mathrm{u}]$ is characterized as the vowel of the back row of the upper rise. In Thai, there is an acoustically and articulately similar vowel. However, when articulating this sound in Russian syllables, violations of the differential and integral signs of the phoneme $/ \mathrm{u} /$ were found. In the position after solid consonants, allophone $[\mathrm{u}]$ was mistakenly realized in $11.4 \%$ of cases. Among the most frequent variants of phonetic error is the implementation of [o] in place of $[\mathrm{u}](4 \%)$. The remaining options for improper reproduction: pronouncing [u] $(3,4 \%)$, diphthongs [iu] $(3,4 \%)$, [io] $(0,3 \%)$ and [ua] $(0,3 \%)$. Errors were admitted mainly in syllables with a voiceless sibilant consonant $/ \check{\mathrm{s}} /$, a voiceless labial $/ \mathrm{p} /$ and in vibrantum $/ \mathrm{r} /$.

We assumed that in the position after soft consonants the utterance of the allophone [iu] would be difficult for the Thais. However, despite the fact that diphthongoidity is not inherent in the Thai phonetic system, cases were noted when subjects correctly implemented this diphthongoid vowel in syllables with sonants $/ \mathrm{n}^{\prime} /$ and $/ \mathrm{m}^{\prime} /(6.5 \%)$. Most often, the allophone [iu] was represented by the non-diphthongoid sound [u] (54.2\%). A special case is that after the soft rear-lingual (in syllables g'u-k'u-x'u), a vowel / it / [26] should be pronounced due to the palatalization of these consonants. Because of the absence of this sound in Thai, the subjects realized this allophone as a monophthong [u] $(23.5 \%)$. Variants for pronouncing the labialized vowel back row of the upper rise are: diphthongs [iu] (10.5\%), [io] (3.3\%), [ua] $(0.7 \%)$, and a combination of vowels [iur] $(0.7 \%)$ and [ir] $(0.7 \%)$.

The analysis of the results of the phonetic sensitivity test of Thais during the imitation of Russian vowels in syllables is summed up in Table 1.

Table 1. Results of testing the phonetic sensitivity of Thais when imitating Russian vowels in syllables $(\mathrm{CV})$. 


\begin{tabular}{|c|c|c|}
\hline $\begin{array}{l}\text { Russian stressed } \\
\text { vowels }\end{array}$ & $\begin{array}{l}\text { Allophones of Russian } \\
\text { stressed vowels }\end{array}$ & $\begin{array}{l}\text { Realization of Russian vowels } \\
\text { in syllables }\end{array}$ \\
\hline \multirow[b]{2}{*}{$/ \mathbf{a} /$} & {$[\mathbf{a}]$} & $\begin{array}{c}{[\mathbf{a}]} \\
{[\mathfrak{x}]} \\
{[\mathrm{u} a]}\end{array}$ \\
\hline & ['ía] & $\begin{array}{r}{[\mathrm{i} a} \\
{[\mathrm{a}]} \\
{[\mathfrak{a}]} \\
{[\mathrm{e}]} \\
{[\mathrm{ia}]}\end{array}$ \\
\hline \multirow[t]{2}{*}{$/ 0 /$} & ["uo] & $\begin{array}{c}\text { ["o] } \\
{[\mathrm{o}]} \\
{[\mathrm{ou}]} \\
{[\mathrm{oi}]} \\
{[\mathrm{ua}]} \\
{[\mathrm{e}]} \\
{[\mathrm{u}]} \\
{[\mathrm{iu}]} \\
{[\mathrm{io}]}\end{array}$ \\
\hline & {$\left[{ }^{\mathbf{y}} \mathbf{0}\right]$} & $\begin{array}{l}{\left[{ }^{\mathrm{y}} \mathrm{O}\right]} \\
{[\gamma]} \\
{[\mathrm{w}]} \\
{[\mathrm{ia}]} \\
{[\mathrm{io}]} \\
{[\mathrm{ua}]} \\
{[\mathrm{ou}]} \\
{[\mathrm{ir}]}\end{array}$ \\
\hline$/ \mathbf{i} /$ & [i] & $\begin{array}{l}{[\mathrm{w}]} \\
{[\mathrm{iu}]} \\
{[\mathrm{i}]} \\
{[\mathfrak{x}]} \\
{[\mathrm{e}]} \\
\end{array}$ \\
\hline \multirow[b]{2}{*}{$/ \mathbf{u} /$} & {$[\mathbf{u}]$} & $\begin{array}{l}{[\mathbf{u}]} \\
{[\mathrm{o}]} \\
{[\mathrm{w}]} \\
{\left[{ }^{\mathrm{i}} \mathrm{u}\right]} \\
{\left[{ }^{\mathrm{i}} \mathrm{o}\right]} \\
{\left[{ }^{\mathrm{u}} \mathrm{a}\right]} \\
\end{array}$ \\
\hline & {$\left[{ }^{\mathrm{y}} \mathbf{u}\right]$} & $\begin{array}{c}{[\mathrm{u}]} \\
{[\mathrm{wu}]} \\
{\left[{ }^{\mathrm{i}} \mathrm{u}\right]} \\
{[\mathrm{io}]} \\
{[\mathrm{ua}]} \\
{[\mathrm{iw}]} \\
{[\mathrm{i}]}\end{array}$ \\
\hline \multirow{2}{*}{$/ \mathbf{e} /$} & {$[\varepsilon]$} & $\begin{array}{c}{[\varepsilon]} \\
{[\mathrm{w}]} \\
{[\mathrm{ei}]} \\
{[\mathrm{wa}]} \\
{[\mathrm{i}]} \\
\end{array}$ \\
\hline & {$\left[{ }^{\mathrm{i}} \mathbf{e}\right]$} & $\begin{array}{c}{[\mathrm{ie}]} \\
{[\mathrm{ei}]} \\
{[\mathfrak{x}]} \\
{[\mathrm{i}]} \\
{[\mathrm{a}]}\end{array}$ \\
\hline
\end{tabular}




\begin{tabular}{|c|c|c|}
\hline & & {$[\mathrm{i}]$} \\
& & \\
& {$[\mathrm{i} /$} & {$[\mathrm{w}]$} \\
& & {$[\mathrm{u}]$} \\
& & {$[æ]$} \\
& & {$[\mathrm{ia}]$} \\
\hline
\end{tabular}

It was expected that the greatest difficulties for the subjects would arise in the implementation of allophones of Russian vowels combined with soft consonants. In some positions deviations from the norm of vowels' pronunciation were noted. Another problem was the non-discrimination of articulatory similar sounds, for example, in syllables with

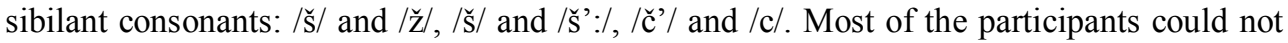
implement hard $/ \mathrm{r} /$ and $/ 1 /$. In this regard, it can be argued that the phonetic disturbances in the imitation of Russian sounds by the Thais were manifested in the implementation of both vowels and consonant sounds, which ultimately led to the incorrect pronunciation of Russian syllables.

\subsection{Consonants}

In most cases, the consonants of the Russian language were replaced by the corresponding Thai sounds. An analysis of the experiments' results shows that the most problematic for the Thais sounds are hissing, back-lingual and all soft consonants.

\subsubsection{Libial stops noisy consonants}

In place of the Russian $/ \mathrm{b} /, 71 \%$ of the subjects reproduced the corresponding Thai lip consonant. In addition, the implementation of this phoneme as a palatalized consonant [ $\mathrm{b}^{\prime}$ ] $(3 \%)$ and with weak palatalization $(1 \%)$ was noted; pronunciation of a voiceless consonant [p] $(16 \%)$, voiceless aspirate [ph] $(8 \%)$, and labial sonant [w] $(1 \%)$.

Only $20 \%$ of the subjects could reproduce the soft voiced consonant [b']. $47 \%$ of the participants in the experiment realized a slightly palatalized sound on the site of this consonant, and $29 \%$ - a hard $/ \mathrm{b} /$. A small number of violations constitute the realization of the voiceless [p] $(2 \%)$ and bilabial [w] $(2 \%)$.

$38 \%$ of the subjects realized instead of hard $/ \mathrm{p} /$ the corresponding Thai dumb labial noisy closure. In addition, pronounced voiced consonant [b] (36\%) and voiceless aspirated [ph] $(16 \%)$.

When the soft phoneme /p'/ was realized, more variants were noted than when the solid $/ \mathrm{p} /$ was pronounced. A weak palatalization was observed in the reproduction of this phoneme $(62 \%) .18 \%$ of the subjects realized the corresponding hard consonant, $7 \%$ - hard voiced [b], $2 \%$ - soft [b']. It should be noted that the soft $/ \mathrm{p}$ '/ was pronounced correctly in $11 \%$ syllables, which means that with the required amount of training exercises, Thais can learn the articulation of this sound.

Errors of Thais in the imitation of lip stoppers are associated with a violation of the differential signs of these consonants: hardness-softness, voiceless-voiced, as well as aspiration of a voiceless hard / $\mathrm{ph} /$, characteristic of the corresponding Thai sound (see table 2).

Table 2. The implementation of Russian labial stops by Thai subjects. 


\begin{tabular}{|c|c|c|c|c|c|c|c|c|}
\hline \multirow{2}{*}{ 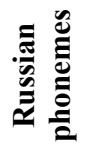 } & \multicolumn{8}{|c|}{ Realization of labial stops (\%) } \\
\hline & [p] & [p'] & [b] & [b’] & weak [p'] & weak [b'] & {$\left[p^{\mathrm{h}}\right]$} & $/ \mathbf{w} /$ \\
\hline$/ \mathbf{p} /$ & 38 & & 36 & & & 9 & 16 & \\
\hline$/ \mathbf{p}^{\prime} /$ & 18 & 11 & 7 & 2 & 62 & & & \\
\hline$/ \mathbf{b} /$ & 16 & & 71 & 3 & & 1 & 8 & 1 \\
\hline /b'/ & 2 & & 29 & 20 & & 47 & & 2 \\
\hline
\end{tabular}

* Fat marked out the correct implementation of Russian labial stops.

Phoneme /f/ subjects were correctly implemented in $87 \%$ of cases. Minor impairments are associated with the realization of a palatalized sound $(6 \%)$ and English labial-dental sound $/ \mathrm{v} /(7 \%)$.

Only $4 \%$ of the subjects could reproduce the soft $/ \mathrm{f} /$. The rest were pronounced with a slightly palatalized labial fissure (67\%), hard /f/ (20\%), hard anterior-speaking voiceless /s/ $(7 \%)$ and hard anterior-voiced voiced $/ \mathrm{z} /(2 \%)$.

Pronouncing the voiced $/ \mathrm{v} /$ and $/ \mathrm{v} /$ caused considerable difficulties for the participants in the experiment due to the lack of sounds in the Thai language. The majority of the subjects realized the English dental [v], the peculiarity of articulation is that the tongue is rounded, its tip touches the upper edge of the lower teeth [57]. This fact corresponds with the results of a study by B. Aymongkhon [2, p. 85]. In a number of cases, /v/ was replaced by a Thai bilabial sonant $[\mathrm{w}](24 \%)$, and fricative [f] $(10 \%)$. Apparently, for the subjects an important phonological sign for $/ \mathrm{v} /$ and $/ \mathrm{v}$ '/ turned out to be labial articulation. Incomplete closure of the lips led to the reproduction of the bilabic [w], available in the Thai system. In addition, the following sounds were pronounced: posterior lingual $[\mathrm{k}](3 \%)$, dull occlusive $[\mathrm{p}](2 \%)$, ringing stop [b] (1\%), sonant [r] (1\%), palatalized [v'] (1\%) and diphthong [iæ] $(1 \%)$. These errors are random and are, most likely, due to the search for articulation of an unusual sound.

When the phoneme $/ \mathrm{v}$ / was realized, violations of various types were committed. Most often, the phoneme was poorly palatalized $(40 \%)$. In place of /v'/ were pronounced: bilabial [w] (24\%), English labial-dental [v] (20\%). In addition, a voiceless labial stop [p] (4\%), a voiced labial stop [b] (2\%), a front hard tongue [d] (2\%), a Thai "non-vocalized and unaffected" tongue [2, p. 67] - [tc] (2\%) and the vowel [iu] (2\%) (see Table 3).

Table 3. Realization of Russian labial fricatives by Thai subjects.

\begin{tabular}{|c|c|c|c|c|c|c|c|c|c|c|c|c|c|c|c|c|}
\hline \multirow{2}{*}{ 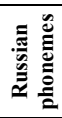 } & \multicolumn{16}{|c|}{ Realization of Russian labial fricatives (\%) } \\
\hline & [f] & {$\left[\mathbf{f}^{\prime}\right]$} & {$[\mathbf{v}]$} & $\begin{array}{l}\text { weak } \\
/ \mathbf{v}^{\prime} /\end{array}$ & $\begin{array}{c}\text { weak } \\
{\left[\mathbf{f}^{\prime}\right]}\end{array}$ & [p] & [b] & {$[\mathbf{r}]$} & [k] & [ttc] & [s] & {$[\mathbf{z}]$} & {$[\mathbf{w}]$} & [d] & ['u] & [iæ] \\
\hline$/ \mathbf{f} /$ & 87 & 6 & 7 & & & & & & & & & & & & & \\
\hline $\mid \mathbf{f}^{\prime} /$ & 20 & 4 & & & 67 & & & & & & 7 & 2 & & & & \\
\hline$/ \mathbf{v} /$ & 10 & & \begin{tabular}{l|l}
57 \\
\end{tabular} & 1 & & 2 & 1 & 1 & 3 & & & & 24 & & & 1 \\
\hline$/ \mathbf{v} \%$ & & & 20 & 40 & & 4 & 2 & & & 2 & & & & 2 & 2 & \\
\hline
\end{tabular}

* Fat marked the correct implementation of Russian labial fricatives.

The greatest number of deviations from the phonetic norms of the Russian language is fixed in the articulation of sonorous $/ \mathrm{v} /$ and $/ \mathrm{v} \%$. Thai bilabial $[\mathrm{w}]$ is realized instead of the fricative labial-dental [v] both in English and in Russian speech. Probably those subjects who have developed the skills of pronouncing the English lip-dental [v], could reproduce it in place of the Russian labial fricative sound.

\subsubsection{Front stops noisy consonants}


The phoneme /t/ was realized by the corresponding Thai sound in $52 \%$ of cases. Pronouncing [d] instead of $/ \mathrm{t} /(26 \%)$ indicates the non-discrimination of these two consonants with native speakers of Thai. The phoneme / $t$ / was also represented by the Thai front aspirate [th] (12\%), the mid-tongue occlusal [t6] (6\%), the bilibial [w] (2\%) and the fricative [f] (2\%) (see Table. 4).

In place of the phoneme $/ \mathrm{t} /$, the subjects reproduced the mid-lingual stopper $/ \mathrm{t} 6 /$ in $71 \%$ of cases. Only $6 \%$ of cases were noted when the Thais realized the sound [ $\mathrm{t}^{\prime}$ ] with weak palatalization. Other variants of implementation are the whistling front-line [s] (13\%), the Thai mid-lingual slot [tch] (6\%), the front-ringed voiced [d] (1\%) and the vowels [iu] (2\%) and [io] (1\%). The appearance of diphthongoid vowels might be explained by the fact that the subjects perceived only the i-shaped transition from the soft consonant to the vowel.

In place of the phoneme $/ \mathrm{d} / 60 \%$ of the participants in the experiment pronounced the corresponding Thai consonant. The utterance of a voiceless hard [t] (14\%) was recorded, which proves the fact that the front-end stoppers $/ \mathrm{t} /$ and $/ \mathrm{d} /$ are not distinguished; $(12 \%)$, anteriorly aspirated [th] (4\%), voiced labial [b] (3\%), slit [f] (2\%) and bilabial [w] (1\%).

The implementation of the phoneme $/ \mathrm{d}$ '/ in most cases was represented by a mid-term, intermittent Thai sound [tc] (71\%). 16\% of the subjects had poorly palatalized [d'], and only $7 \%$ were able to reproduce the soft voiced front-lingual closure. In addition to these options, the pronunciation of vowels of diphthongoid sounds were found: [io] (2\%), [iu] (2\%) and [ia] $(2 \%)$.

Table 4. The implementation of Russian front-tongue stoppers by Thai subjects.

\begin{tabular}{|c|c|c|c|c|c|c|c|c|c|c|c|c|c|c|c|c|}
\hline 亗 & \multicolumn{16}{|c|}{ Realization of Russian front-tongue stoppers (\%) } \\
\hline 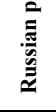 & $\begin{array}{l}\text { [t } \\
\text { ] }\end{array}$ & $\begin{array}{c}{\left[\mathbf{t}^{\mathbf{}}\right.} \\
\mathrm{]}\end{array}$ & $\begin{array}{c}{[\mathbf{d}} \\
]\end{array}$ & $\begin{array}{c}{\left[\mathbf{d}^{\prime}\right.} \\
]\end{array}$ & $\begin{array}{c}\text { wea } \\
\mathbf{k} \\
{\left[\mathbf{t}^{\prime}\right]}\end{array}$ & $\begin{array}{c}\text { wea } \\
\mathbf{k} \\
\text { [d'] }\end{array}$ & $\begin{array}{c}\text { [tc } \\
]\end{array}$ & $\begin{array}{c}{\left[\mathbf{t}^{\mathbf{h}}\right.} \\
]\end{array}$ & $\begin{array}{c}\text { [b } \\
\text { ] }\end{array}$ & $\begin{array}{c}\text { [f } \\
\text { ] }\end{array}$ & $\begin{array}{c}\mathbf{I t c}^{\mathbf{h}} \\
]\end{array}$ & $\begin{array}{c}\text { [s } \\
\text { ] }\end{array}$ & $\begin{array}{c}\text { [w } \\
\text { ] }\end{array}$ & $\begin{array}{c}{ }^{\mathbf{i}} \mathbf{o} \\
]\end{array}$ & $\begin{array}{c}{\left[{ }^{\mathrm{i}} \mathbf{u}\right.} \\
]\end{array}$ & $\begin{array}{c}{\left[^{\mathrm{i}} \mathbf{a}\right.} \\
]\end{array}$ \\
\hline$/ \mathbf{t} /$ & $\begin{array}{l}5 \\
2\end{array}$ & & 26 & & & & 6 & 12 & & 2 & & & 2 & & & \\
\hline $\begin{array}{c}/ \mathbf{t}^{\mathbf{}} \\
/\end{array}$ & & - & 1 & & 6 & & 71 & & & & 6 & $\begin{array}{l}1 \\
3\end{array}$ & & 1 & 2 & \\
\hline$/ \mathbf{d} /$ & $\begin{array}{l}1 \\
4\end{array}$ & - & 60 & & & & 12 & 4 & 3 & 2 & & & 1 & & & \\
\hline $\begin{array}{c}/ \mathbf{d}, \\
/\end{array}$ & & & & 7 & & 16 & 71 & & & & & & & 2 & 2 & 2 \\
\hline
\end{tabular}

* In bold is the correct implementation of Russian pre-verbal closure.

\subsubsection{Affricates}

The Russian affricate /c/ causes special difficulties for Thais, since it is absent in their native language. In most cases, / c / was represented by the Thai apical [s] (57\%). This means that for Thai people the relevant feature of the Russian firm affricate is the slotted element. In addition, a mid-lingual stop [t6] (34\%) was recorded, possibly due to the awareness of the inhomogeneity of the articulation of this sound and its difference from the Thai slit $/ \mathrm{s} /$. Not finding an analogue of the heard sound in the Thai language, the subjects realized a similar, in their opinion, consonant $/ \mathrm{t} 6 / .9 \%$ of the subjects were pronounced an anteriorly voiced slit sound of English [z] (see table 5). 
It should be said that in accordance with the symbols of the international phonetic alphabet, the Russian voiceless soft affricate has the same designation as the Thai mid-lingual stopper /tc/ (จ). In our experiment, $71 \%$ of the subjects on the site of Russian affricates /č'/ implemented a half-lingual slit [tch]. The rest of the participants pronounced Thai apical whistling $[\mathrm{s}](17 \%)$ and averaginal blind ([11]), and, for unclear reasons, Central European sonant $[1](1 \%)$.

The reason for the implementation of the mid-lingual stopper /to / in place / $\check{c}$ '/ is the absence of palatalized $/ \mathrm{t}^{\prime} /$ and $/ \breve{\mathbf{s}}^{\prime} /$ in Thai, so subjects could perceive mild / $/ \check{c}^{\prime} /$ as based on "false similarity". In order to realize the given consonant, subjects pronounced a sound similar to them, i.e. also closed, but medium-lingual. Articulatory descriptions of Thai /t6/ and Russian /č'/ are fundamentally different from each other. N.A. Lyubimova characterizes the affricate /č/ as follows: "consonant /c'/ is in Russian an antero-lingual double-focus voiceless soft affricate" [17, p.119]. B. Aymongkhon describes a similar Thai sound as a "non-voiced and unaffected" semicolonical consonant /h/ [2, p. 67].

Table 5. The implementation of Russian affricates by Thai subjects.

\begin{tabular}{|c|c|c|c|c|c|c|c|}
\hline \multirow{2}{*}{ 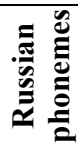 } & \multicolumn{7}{|c|}{ Realization of Russian affricates (\%) } \\
\hline & $/ \mathbf{c} /$ & $/ \check{\mathbf{c}}^{\prime} /$ & {$[\mathbf{s}]$} & {$[\mathrm{z}]$} & [tt] & {$\left[\mathbf{t c}^{\mathrm{h}}\right]$} & [l] \\
\hline$/ \mathbf{c} /$ & - & & 57 & 9 & 34 & & \\
\hline$/ \check{\mathbf{c}} ' /$ & & - & 17 & & 11 & 71 & 1 \\
\hline
\end{tabular}

* In bold is the correct implementation of Russian affricate.

According to the classification of Thai consonants, proposed by M.R. Kalaya Tingsabadh and Arthur S. Abramsom, consonant [t6] - "post-alveolar affricate", i.e. post-alveolar affricate, which is opposed to the consonant [tch] only by the presence-absence of aspiration $[25$, p. 25]. The difficulty in determining the articulatory properties of a given sound can be explained by the reason for its realization by the Thais instead of the Russian stop, slit and affricate.

\subsubsection{Anteroposterior slit noisy consonants}

Instead of the Russian phoneme /s/ $65 \%$ of the subjects reproduced the corresponding Thai sound - apical non-polarized [2, p. 88] (see Table 06). Participants in the experiment also realized an apical slit [z], similar to the front-language slit sound of English (16\%), which indicates the undifferentiation of the sounds [s] and [z]; Thai half-lingual slit [tch] $(18 \%)$, possibly under the influence of sibilant $[\mathrm{h}],[\mathrm{w}],[\mathrm{w}]$ in neighboring syllables; and a medium-lingual stop [t6] (1\%).

The phoneme $/ \mathrm{s}$ / was reproduced by the subjects as a Thai softened apical non-polarized sound $(29 \%)$ and non-palatalized (29\%). However, in most cases, instead of this phoneme, the tongue-slit [t6h] (38\%) and the mid-lingual stop [t6] (4\%) were pronounced.

According to Aymongkhon B. [2, p.88], due to the absence of the Russian sonorous hard whistling / $/ \mathrm{z} /$ in the Thai language, the subjects correlated this Russian phoneme with the English-speaking frontal slit agreeing to it (31\%). However, most often the Thai apical nonpolarized sound [s] (66\%) was realized. In addition, a mid-lingual stopper/t6/ (3\%) was also introduced.

Simulation of the phoneme / $z^{\prime} /$ caused certain difficulties for the subjects. This phoneme was realized either as a weakly palatalized voiced consonant [z'] $(10 \%)$, or as a velarized $[z]$ $(16 \%)$. In the remaining $19 \%$ of cases, the phoneme was represented by the Thai apical whistling $/ \mathrm{s} /$. 
Instead of the phoneme /š/, most subjects produced a Thai-language slit [tch] (70\%), due to the lack of sizzling in the Thai language. The list of erroneous variants of pronouncing / $\check{\mathrm{s}}$ / includes such implementations as the apical blank wheezing [s] (15\%), the middle tongue stop [t6] $(10 \%)$, the front tongue sizzling [ $[\check{z}](1 \%)$, the front slit $[\mathrm{t}](1 \%)$, sonorous whistling [z] (1\%), sonant [1] (1\%) and anterior slit [f] (1\%).

The Russian phoneme /ž/ does not have a similar sound in the Thai language. Nevertheless, $13 \%$ of the subjects could reproduce this sound in combination with the vowel. But in most cases the Russian sonorous hissing was reproduced as a Thai slate [tch] (57\%). Other implementations of sonorous sibilant are the following: the mid-tongue occlusal [t6] $(13 \%)$, the front-ringed voiced [d] $(2 \%)$, the voiceless stop [t] $(2 \%)$, the voiceless aspirate [th] $(2 \%),[\mathrm{z}](2 \%)$, dull whistling [s] (7\%), and lateral sonant [1] (2\%). In our opinion, such a wide variety of erroneous options for the realization of the Russian sonorous sibilant is due to articulatory difficulties for the Thais.

Table 6. Implementation of Russian front sibiliants consonants by Thai subjects.

\begin{tabular}{|c|c|c|c|c|c|c|c|c|c|c|c|c|c|}
\hline \multirow{2}{*}{ 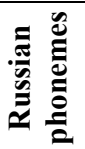 } & \multicolumn{13}{|c|}{ Realization of front sibiliants (\%) } \\
\hline & {$[\mathbf{s}]$} & [s'] & [z] & [z'] & $/ / \mathbf{s} /$ & $|\mathbf{z}|$ & [క̌š: :] & {$\left[\mathbf{t c}^{\mathrm{h}}\right]$} & {$\left[\mathbf{t}^{\mathrm{h}}\right]$} & {$[\mathbf{t}]$} & [d] & [tc] & [l] \\
\hline$/ \mathbf{s} /$ & 65 & & 16 & & & & & 18 & & & & 1 & \\
\hline$/ \mathbf{s} \%$ & 29 & 29 & & & & & & 38 & & & & 4 & \\
\hline $\mid \mathbf{z} /$ & 66 & & 31 & & & & & & & & & 3 & \\
\hline$\left|\mathbf{z}^{\prime}\right|$ & 42 & & 36 & 22 & & & & & & & & & \\
\hline$/ \check{\mathbf{s}} /$ & 15 & & & & - & 1 & & 70 & & 1 & & 10 & 1 \\
\hline $\mid \check{\mathbf{z}}$ & 7 & & 2 & & & 13 & & 57 & 2 & 2 & 2 & 13 & 2 \\
\hline /“'s':/ & 31 & & & & & & - & 49 & & & & 20 & \\
\hline
\end{tabular}

* In bold is the correct implementation of Russian front-slit.

As you know, in the Thai language there is no hissing phoneme / ̌s':/. In most cases, it was implemented as a Thai-language slit [tch] (49\%). Instead of the Russian soft hissing long, the subjects pronounced the apical sound [s] (31\%) and the Thai mid-lingual stop [t6] (20\%). This is due to the non-distinction between single-focus and two-focus consonants.

\subsubsection{Velar stops consonants}

The majority of the subjects realized the Russian velar stop / $\mathrm{k} /$ as the corresponding Thai velar $(78 \%)$. In other cases, such sounds as Thai velar aspirate $[\mathrm{kh}](16 \%)$ and pharyngeal $[\mathrm{h}]$ $(2 \%)$, as well as bilabial $[\mathrm{w}](4 \%)$ were pronounced (see Table 07$)$.

The absence of a soft phoneme $/ \mathrm{k}^{\prime} /$ in Thai language provoked the realization of a hard, closed $[\mathrm{k}](65 \%)$. Implications of velar aspirated [kh] $(22 \%)$ and a slightly palatalized velar $(13 \%)$ were noted.

The phoneme $/ \mathrm{g} /$ was reproduced as a velar $[\mathrm{k}](69 \%)$, since in Thai language there is no analogue of the Russian bell-shaped rear-phonemic phoneme. In addition, the realization of an explosive stop aspirate $[\mathrm{kh}](18 \%)$ was recorded. The remaining variants are represented by Thai pharyngeal $[\mathrm{h}](7 \%)$, bilabial $[\mathrm{w}](4 \%)$ and sonorous labial $[\mathrm{b}](2 \%)$.

The soft phoneme $/ \mathrm{g} /$ in most cases was also realized by the stopper deaf $[\mathrm{k}](62 \%)$. In addition, a sonorous weakly palatalized posterior-lingual consonant was found (38\%).

Aymmongkhon B., referring to the opinion of A.V. Ventsov and A. Martine, write about the difficulty for the Thais to realize the voiced back-lingual abrupt sounds: "the formation of the binder-collar bones in comparison with the front-lingual and labial ones is closer to the glottis. Therefore, at the time of the formation of their bows, the resonator is filled with a smaller amount of air and this prevented the difference between intraoral and subglottic pressure, which is necessary for the realization of the voiced consonant" [Cit. on 2, p. 94]. 
Table 7. Implementation of Russian velar consonants by Thai subjects.

\begin{tabular}{|c|c|c|c|c|c|c|c|c|}
\hline \multirow{2}{*}{ 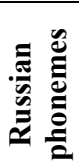 } & \multicolumn{8}{|c|}{ Realization of velar consonants (\%) } \\
\hline & $/ \mathrm{k} /$ & $/ \mathrm{k}^{\prime} /$ & $/ \mathrm{k}^{\mathrm{h}} /$ & $/ \mathrm{k}^{\mathrm{h}} /$ & $\mid \mathrm{x} /$ & $/ \mathrm{h} /$ & $/ \mathrm{w} /$ & $/ \mathrm{b} /$ \\
\hline$/ \mathbf{k} /$ & 78 & & 16 & & & 2 & 4 & \\
\hline$/ \mathbf{k}^{\prime} /$ & 65 & - & 22 & 13 & & & & \\
\hline$/ \mathrm{g} /$ & 69 & & 18 & & & 7 & 4 & 2 \\
\hline$/ \mathrm{g} \%$ & 62 & 38 & & & & & & \\
\hline$/ \mathbf{x} /$ & 4 & & 44 & & 2 & 50 & & \\
\hline$/ \mathbf{x} \%$ & & & 18 & & & 82 & & \\
\hline
\end{tabular}

The absence of a slotted posterior phoneme $/ \mathrm{x} /$ in Thai means the fact that the subjects were pronounced Thai pharyngeal $[\mathrm{h}](50 \%)$. In other cases, the Thais realized explosive stoppers: aspirated $[\mathrm{kh}](44 \%)$ and non-respiratory $[\mathrm{k}](4 \%)$. At the same time, $2 \%$ of the subjects were able to pronounce the Russian back-lingual fricative $[\mathrm{x}]$.

The phoneme $/ \mathrm{x}^{\prime} /$, also unmatched in Thai, was most often realized as a pharyngeal [h] $(82 \%) .18 \%$ of the participants in the experiment reproduced the aspirated aspirate $[\mathrm{kh}]$.

\subsubsection{Sonants}

As expected, the phoneme $/ \mathrm{m} /$ did not cause any special difficulties for the subjects, because in Thai there is a corresponding consonant, so they realized this sonant correctly in $91 \%$ of cases. $9 \%$ of violations - the implementation of a labial sonant with weak palatalization (see Table 8).

Despite the fact that the soft phoneme $/ \mathrm{m}$ '/ is absent in Thai, $11 \%$ of its normative realizations are noted. In most cases, $/ \mathrm{m}$ '/ was realized as a slightly palatalized sound $(73 \%)$. $16 \%$ of the subjects reproduced non-palatalized [m].

Pronouncing the nasal anteroposterior $/ \mathrm{n} /$ also was not difficult for many participants in the experiment. This sonant was replaced by the corresponding Thai consonant (82\%), which, according to acoustic signs, almost does not differ from the Russian nasal sonant. The realization of $/ \mathrm{n} /$ as a weakly palatalized consonant was found (4\%). In other cases, reproduction of the labial sonant $/ \mathrm{m} /(13 \%)$ was noted, which indicates the possibility of nondecreasing the phonemes $/ \mathrm{n} /$ and $/ \mathrm{m} /$.

With the implementation of the phoneme $/ \mathrm{n} \%$, more variants of utterance were recorded. The soft nasal sonant $/ \mathrm{n}$ '/ was realized mainly as a poorly palatalized consonant (51\%), nonpalatalized $(9 \%)$ and labial sonant $[\mathrm{m}](11 \%)$. It is important that soft $/ \mathrm{n}$ '/ has a greater number of correct realizations than other soft consonants (18\%). In addition, some subjects pronounced the mid-lingual sonant [j] in n'a-n'u syllables $(11 \%)$.

The apical velarized / $\mathbf{t}$ was reproduced as the corresponding Thai slotted lateral sonant [1] $(63 \%)$. In $31 \%$ of cases, a trembling sonant [r] was realized. In addition, the pronunciation of retroflex slit English [R] (6\%) was found.

Table 8. Realization of Russian sonants by Thai subjects. 


\begin{tabular}{|c|c|c|c|c|c|c|c|c|c|c|c|c|c|}
\hline & [m] & $\begin{array}{c}\text { weak } \\
\text { [m'] }\end{array}$ & $\left./ \mathbf{m}^{\prime}\right]$ & [n] & $\begin{array}{c}\text { weak } \\
\text { [n'] }\end{array}$ & [n'] & [l] & $\begin{array}{c}\text { weak } \\
/ \mathbf{l}^{\prime} /\end{array}$ & {$[\mathbf{r}]$} & $\begin{array}{c}\text { weak } \\
{\left[\mathbf{r}^{\prime}\right]}\end{array}$ & {$[\mathbf{R}]$} & [h] & {$[\mathbf{j}]$} \\
\hline$/ \mathbf{m} /$ & 91 & 9 & & & & & & & & & & & \\
\hline$/ \mathrm{m}^{\prime} /$ & 16 & 73 & 11 & & & & & & & & & & \\
\hline$/ \mathbf{n} /$ & 13 & & & 82 & 4 & & & & & & & & \\
\hline$/ \mathbf{n}^{\prime} /$ & 11 & & & 9 & 51 & 18 & & & & & & & 11 \\
\hline$/ \mathbf{t} /$ & & & & & & & 63 & & 31 & & 6 & & \\
\hline$/ \mathbf{l} /$ & & & & & & & 49 & 6 & 29 & 10 & 6 & & \\
\hline$/ \mathbf{r} /$ & & & & & & & 1 & & 81 & 7 & 10 & & \\
\hline$/ \mathbf{r}^{\prime} /$ & & & & & & & 3 & & 27 & 59 & 11 & & \\
\hline$/ \mathbf{j} /$ & & & & & & & & & & & & 11 & 89 \\
\hline
\end{tabular}

* In bold is the correct implementation of Russian sonants.

Soft $/ 1$ ' was most often pronounced as the corresponding slit lateral sonant of Thai [1] $(49 \%)$ and with weak palatalization (6\%). The second in frequency was the realization of $/ 1$ '/ as vibrant $[\mathrm{r}](29 \%)$. The pronunciation of a slightly palatalized sonant $[\mathrm{r}](10 \%)$ was also found. The implementation of retroflex slit English [R] $(6 \%)$ is noted.

$81 \%$ of the subjects realized on the site of the phoneme $/ \mathrm{r} /$ the corresponding Thai trembling consonant and the slightly palatalized sonant (7\%). Here, retroflex slit English [R] $(11 \%)$ was also identified. Only in one case the phoneme was reproduced as a Thai lateral slot $[1](1 \%)$.

The phoneme $/ \mathrm{r}$ '/ was reproduced as a weakly palatalized sonant $(59 \%)$ and as the corresponding Thai non-palatalized sonant [r] (27\%). Retroflex gap was realized by $11 \%$ of the subjects. An insignificant number of non-normative realization of a soft vibrant (3\%) is the reproduction of a slotted lateral [1].

The middle-language slit sonant $/ \mathrm{j} /$ was reproduced as the corresponding Thai in $89 \%$ of cases. Erroneous implementation is the pronunciation of the pharyngeal $/ \mathrm{h} /(11 \%)$. The realization of pharingal sound most often appeared when the syllable was spoken [ji]. In this position, sonant $/ \mathrm{j} /$ can provoke non-distinction of the middle-language [j] and pharyngeal [h].

\section{Conclusion}

An analysis of the results of phonetic sensitivity in the Thais makes it possible to reveal the similarity and difference in the articulatory characteristics of the sounds of interacting languages (see Fig. 1.*).

The obtained results indicate that in the zone of negative Russian-Thai interference there are the following Russian consonants: front-line $/ \mathrm{t} ' /, / \mathrm{d} / /$; affricates $/ \mathrm{c} /, / \mathrm{c̆}^{\prime} /$; sizzling front-

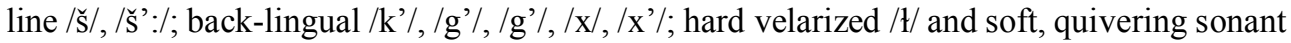
$/ \mathrm{r} \%$

Since in the imitation of Russian syllables, the Thais are not aware of the consonants' contrast on the grounds of "hardness-softness" and "voiceless-voiced", special work is required to set soft sounds and develop skills for distinguishing sounds from voiceless-voiced, especially for such pairs of sounds as $/ \mathrm{b}-\mathrm{p} /, / \mathrm{d}-\mathrm{t} /, / \mathrm{f}-\mathrm{v} /$ and $/ \mathrm{r}-\mathrm{t} /$.

It should be borne in mind that the presence in the Thai language of aspirated front-language and back-lingual consonants, bilabial $[\mathrm{w}]$ and pharyngeal $[\mathrm{h}]$ may interfere with the formation of phonetic skills in Russian. 


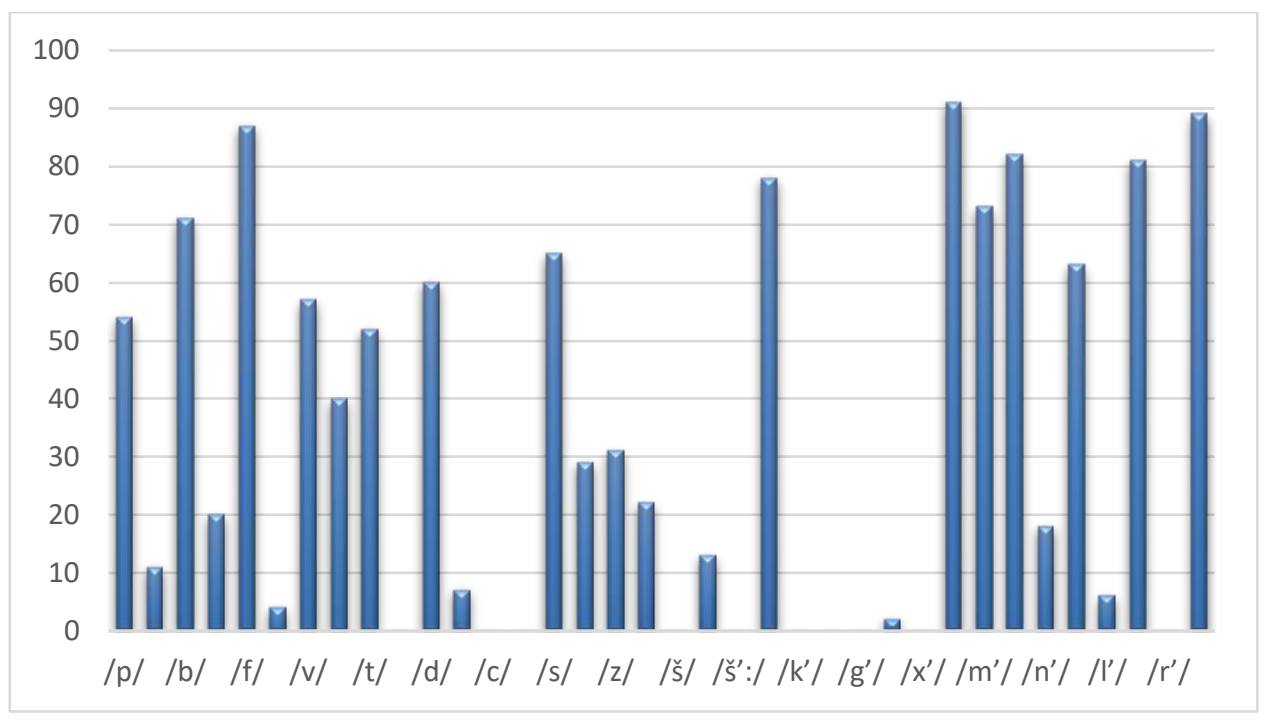

Fig. 1. Correct implementation of Russian consonants by Thai subjects (test of phonetic sensitivity, \%).

Our experiment confirmed the idea that the source of phonetic errors in a foreign language can be a previously learned non-native language (in our case, English).

\section{References}

1. E. G. Azimov, A. N. Schukin, A new dictionary of methodological terms and concepts (Theory and practice of Language teaching) (Publishing house IKAR, Moscow, 2009)

2. A. Bongkot. Thai-Russian phonetic interference: segment level: PhD abstract (St. Petersburg, 2008)

3. L. V. Bondarko, Phonetics of modern Russian language (Publishing house of the St. Petersburg State University, St. Petersburg, 1998)

4. R. C. Calfee, P. Lindamood, C. Lindamood, Journal of Educational Psychology, 64, 3 (1973)

5. L. Chistovich, A. Golusina, V. Lublinskaja, Psychological methods in speech perception research. Zeitschrift für Phonetic (1968)

6. J. Downing (Ed.), Comparative reading (Macmillan, New York, 1973)

7. B. Fox, D. K. Routh, Journal of Psycholinguistic Research, 4 (1975)

8. A. A. Frolov, Vestnik Vyatskogo Gosudarstvennogo Gumanitarnogo Unuversiteta, 3, 3 (2009)

9. T. G. Gillon, Phonological awareness: from research to practice (Guilford Press, New York, 2004)

10. L. V. Bondarko, L. A. Verbitskaya, Interference of sound systems (LSU, Leningrad, 1987)

11. E. Kh. Karpovnikova, The development linguistic sensitivity of first-graders to the morpheme (Moscow, 2017).

12. E. A. Kislitsyina, Phonetic tests as a diagnostic tool and control when teaching Russian to Chinese students-non-philologists: the elementary level (St. Petersburg, 1995) 
13. T. M. Kolesnikova, The reliance on linguistic flair in teaching Russian language in primary school (Moscow, 2017).

14. G. N. Lebedeva, The perception of non-native vowels of the language (experimental phonetic research on a material of English and Russian languages) (Leningrad, 1982)

15. I. Y. Liberman, Bulletin of the Orton Society, 23 (1973)

16. I. Y. Liberman, D. Shankweiler, F. W. Fischer, B. J. Carter, Journal of Experimental Child Psychology, 18 (1974)

17. N. A. Lyubimova, Linguistic foundations for teaching the articulation of Russian sounds. Formation and correction. (Russkiy yazyik-Kursyi, Moscow, 2011)

18. J. Requin (Ed.), Anticipation and behaviour (1980)

19. K. S. Ogorodnikova, Versatile and phonological space of vowels (Leningrad, 1983)

20. L. A. Pufpaff, Psychology in the Schools, 46, 7 (2009)

21. N. G. Zagoruyko, G. Ya. Voloshin (Eds.), Recognition of auditory images (Nauka, Novosibirsk, 1970)

22. A. V. Schepilova, Theory and methods of teaching French as a second language foreign: a textbook for University students studying on specialty (Humanitarian Publishing Centre VLADOS, Moscow, 2005)

23. P. Gough, L. Ehri, R. Treiman (Eds.), Reading acquisition (Laurence Erlbaum Hillsdale, NJ, 1992)

24. E. A. Shtulman, Foreign Languages at School, 1 (1980)

25. K. Tingsabadh, A. S. Abramson, Thai. Journal of the International phonetic Association, 23 (1993)

26. A. A. Verbitskiy, Encyclopaedic dictionary of psychology and pedagogy (Moscow, 2013)

27. Close central rounded vowel (https://en.wikipedia.org/wiki/Close_central_rounded - vowel) 